ci s trans I somer i smanong the Oct ahedral Di aquabi s( opt i cal I y act i ve $C$ - subst i t ut ed et hyl enedi ami ne) ni ckel (II) Compl exes and Thei $r$ Ther mal React i on Products. An Expl anat $i$ on for a Vari ety in Col or s and Ster eochemistry of Li f schi tz Compl exes

\begin{tabular}{|l|l|}
\hline 著者 & $\begin{array}{l}\text { I har a Yoshi nor i, Saki no Tonom , I shi kawa } \\
\text { M eko, Koyat a Takanor i }\end{array}$ \\
\hline $\begin{array}{l}\text { j our nal or } \\
\text { publ i cat i on t i t l e }\end{array}$ & Bul I et i n of the Chem cal Soci et y of Japan \\
\hline vol une & 70 \\
\hline number & 12 \\
\hline page r ange & $3025-3029$ \\
\hline year & $1997-01-01$ \\
\hline URL & ht t p: //hdl . handl e. net /2297/37514 \\
\hline
\end{tabular}




\title{
cis-trans Isomerism among the Octahedral Diaquabis(optically active $C$-substituted ethylenediamine)nickel(II) Complexes and Their Thermal Reaction Products. An Explanation for a Variety in Colors and Stereochemistry of Lifschitz Complexes
}

\author{
Yoshinori Thara, ${ }^{*}$ Tomomi Sakino, Mieko Ishikawa, and Takanori Koyata \\ Laboratory of Chemistry, Faculty of Education, Kanazawa University, Kakumamachi, Kanazawa 920-11
}

(Received June 26, 1997)

\begin{abstract}
The solid-phase thermal reactions of trans-diaquabis(diamine)nickel(II) complexes (trans- $\left[\mathrm{Ni}(\text { diamine })_{2}\left(\mathrm{H}_{2} \mathrm{O}\right)_{2}\right] \mathrm{X}_{2}$ ) were investigated by means of TG/DTA and DSC, and high-temperature electronic spectrometry, where the diamine is an optically active diamine such as (1S,2S)-1,2-diphenyl-1,2-ethanediamine or (S)-4-methyl-1,2-pentanediamine, and X is $\mathrm{Cl}^{-}, \mathrm{Br}^{-}$, or $\mathrm{NO}_{3}{ }^{-}$. Several complexes were peculiarly transformed into cis-[NiX $\left(\mathrm{Niamine}_{2}\right]$ upon thermal deaquationanation, and then isomerized to trans-[ $\left.\left[\mathrm{NiX}_{2} \text { (diamine) }\right)_{2}\right]$ upon further heating. The results were in contrast to the reactions of the complexes with the corresponding racemic diamines which underwent a simple deaquation-anation, retaining an original trans configuration. The differences must come from a slight difference in the conformation of diamine ligands between trans- $\left[\mathrm{Ni}(R\right.$-diamine $)(S$-diamine $\left.)\left(\mathrm{H}_{2} \mathrm{O}\right)_{2}\right] \mathrm{X}_{2}$ which is obtained for the rac-diamines and trans- $[\mathrm{Ni}(R$ - or $S$-diamine $\left.)_{2}\left(\mathrm{H}_{2} \mathrm{O}\right)_{2}\right] \mathrm{X}_{2}$ which is obtained for the optically active diamines.
\end{abstract}

Bis( $C$-substituted ethylenediamine)nickel(II) complexes normally assume a square planar or octahedral structure, and they are familiar to us as Lifschitz complexes ${ }^{1)}$ which readily undergo deaquation, deaquation-anation or isomeric transformation between the two structures, showing a drastic change in color when they are stored in a desiccator, and suspended or dissolved in various solvents. The elucidation of a manifold stereochemistry observed in such complexes has been a fascinating problem.

We have currently studied the coordination structures of many diaquabis( $C$-substituted ethylenediamine)nickel(II) complexes and the products of their solid-phase thermal reactions, and the effects of $C$-substituent group(s) upon their structural changes during thermal treatments. ${ }^{2)}$ In the course of these studies, it has been clarified that some complexes undergo thermally induced structural isomerization from square planar to octahedral with drastic changes in color and spin state. ${ }^{3)}$ In addition, it has also been found that the diaqua complexes prepared as the starting materials of thermal reactions are all trans, while the dianiono complexes obtained by thermal deaquation-anation of the above diaqua complexes assume a cis configuration only in a few limited cases. ${ }^{45}$ ) One of the rare cases is the group of complexes with unsymmetric diamines such as 2-methyl-1,2-propanediamine and 1-benzyl-1,2-ethanediamine. ${ }^{4)}$ Another is the complexes with an optically active diamine, $(1 R, 2 R)-1,2$-cyclohexanediamine $\left(R\right.$-chxn). ${ }^{5)}$ The latter case is particularly interesting because the thermal reactions of the corresponding complexes with the racemate ( $r a c$-chxn) differ from those with
$R$-chxn, producing the trans-dianiono complexes by thermal deaquation-anation, although $R$-chxn and rac-chxn form complexes with the same composition and structure (trans$\left.[\mathrm{Ni} \text { (diamine) })_{2}\left(\mathrm{H}_{2} \mathrm{O}\right)_{2}\right] \mathrm{X}_{2}: \mathrm{X}=\mathrm{Br}^{-}$or $\mathrm{NO}_{3}{ }^{-}$) as the starting materials of thermal reactions.

In a continuation of these studies, to clarify the details of the effects of $C$-substituent group(s) upon cis-trans isomerism among the diaqua and dianiono complexes, the present study deals with the stereochemical changes upon heating of the complexes with optically active diamines, $(1 S, 2 S)$-1,2-diphenyl-1,2-ethanediamine ( $S$-stien) or (S)-4methyl-1,2-pentanediamine ( $S$-mpen). The results will be discussed and compared with those of the corresponding racemic diamines. $\left.{ }^{3,6}\right)$

\section{Experimental}

Materials. (1S,2S)-1,2-Diphenyl-1,2-ethanediamine ( $S$-stien) of commercial reagent grade was used without further purification. (S)-4-Methyl-1,2-pentanediamine ( $S$-mpen) was prepared as follows. (S)-Leucine methyl ester (methyl 2-amino-4-methylpentanoate) was converted into $(S)$-2-amino-4-methylpentanamide by the method of Arpesella et al. ${ }^{7)}$ (S)-4-Methyl-1,2-pentanediamine was obtained by reducing the amide with $\mathrm{LiAlH}_{4}$ according to the procedure described by Yano et al ${ }^{8)}$ The specific rotation of $S$-mpen hydrochloride prepared, $[\alpha]_{\mathrm{D}}^{20}$, in dry methanol was $-13.9^{\circ}$.

The complexes, trans- $\left[\mathrm{Ni}\right.$ (diamine) $\left.{ }_{2}\left(\mathrm{H}_{2} \mathrm{O}\right)_{2}\right] \mathrm{X}_{2}$ (where diamine is $S$-stien or $S$-mpen and $\mathrm{X}$ is $\mathrm{Cl}^{-}, \mathrm{Br}^{-}$, or $\mathrm{NO}_{3}^{-}$), were prepared by the following method. To an aqueous solution of a nickel(II) salt, $\mathrm{NiX}_{2} \cdot n \mathrm{H}_{2} \mathrm{O}\left(\mathrm{X}\right.$ is $\mathrm{Cl}^{-}, \mathrm{Br}^{-}$, or $\left.\mathrm{NO}_{3}^{-}\right)$, a methanolic solution of $S$ stien or $S$-mpen was added dropwise in the molar ratio of $1: 2$. The 
solutions were allowed to stand for several days to precipitate the desired bis-type complexes. The violet crystals which deposited were collected by filtration and washed with ethanol and diethyl ether. They were recrystallized from water. Elemental analyses of the complexes gave the following data. Found: C, 55.51; $\mathrm{H}$, $6.05 ; \mathrm{N}, 9.21 \%$. Calcd for $\left[\mathrm{Ni}(\mathrm{S} \text {-stien })_{2}\left(\mathrm{H}_{2} \mathrm{O}\right)_{2}\right] \mathrm{Cl}_{2} \cdot \mathrm{H}_{2} \mathrm{O}: \mathrm{C}, 55.29$; $\mathrm{H}, 6.30 ; \mathrm{N}, 9.21 \%$. Found: C, 49.10; H, 5.39; N, 8.10\%. Calcd for $\left[\mathrm{Ni}(\mathrm{S} \text {-stien })_{2}\left(\mathrm{H}_{2} \mathrm{O}\right)_{2}\right] \mathrm{Br}_{2}: \mathrm{C}, 49.52 ; \mathrm{H}, 5.34 ; \mathrm{N}, 8.25 \%$. Found: C, 49.31; H, 5.42; N, 12.31\%. Calcd for [Ni(S-stien $\left.)_{2}\left(\mathrm{H}_{2} \mathrm{O}\right)_{2}\right]-$ $\left(\mathrm{NO}_{3}\right)_{2} \cdot 2 \mathrm{H}_{2} \mathrm{O}: \mathrm{C}, 49.50 ; \mathrm{H}, 5.93 ; \mathrm{N}, 12.37 \%$. Found: $\mathrm{C}, 33.70$; $\mathrm{H}, 8.99 ; \mathrm{N}, 13.18 \%$. Calcd for $\left[\mathrm{Ni}(S \text {-mpen })_{2}\left(\mathrm{H}_{2} \mathrm{O}\right)_{2}\right] \mathrm{Cl}_{2} \cdot 1.5 \mathrm{H}_{2} \mathrm{O}$ : C, 33.91; H, 9.25; N, 13.18\%. Found: C, 29.27; H, 6.81; N, $11.32 \%$. Calcd for $\left[\mathrm{Ni}(S \text {-mpen })_{2}\left(\mathrm{H}_{2} \mathrm{O}\right)_{2}\right] \mathrm{Br}_{2}: \mathrm{C}, 29.60 ; \mathrm{H}, 7.45 ; \mathrm{N}$, 11.51\%. Found: $\mathrm{C}, 31.21 ; \mathrm{H}, 8.31 ; \mathrm{N}, 18.39 \%$. Calcd for [Ni(Smpen $\left.)_{2}\left(\mathrm{H}_{2} \mathrm{O}\right)_{2}\right]\left(\mathrm{NO}_{3}\right)_{2} \cdot 0.5 \mathrm{H}_{2} \mathrm{O}: \mathrm{C}, 31.32 ; \mathrm{H}, 8.10 ; \mathrm{N}, 18.26 \%$.

Measurements. Optical rotation was measured by a JASCO DIT-4 polarimeter. Simultaneous TG-DTA or DSC measurements were carried out with a Seiko SSC/580 TG/DTA-30 or DSC-10 apparatus. Each run of TG-DTA was under a constant flow of nitrogen $\left(200 \mathrm{ml} \mathrm{min}^{-1}\right)$ at a heating rate of $2{ }^{\circ} \mathrm{Cmin}^{-1}$; about 20 $\mathrm{mg}$ of sample was used. The electronic spectra in the solid phase were measured by a diffuse reflectance method with a JASCO V$570 \mathrm{UV} / \mathrm{vis} / \mathrm{NIR}$ spectrophotometer equipped with a reflection attachment. The spectra at elevated temperatures were monitored by use of a JASCO heating cell, which was set up on the apparatus and was controlled by a Toho Denshi BX-304 temperature controller equipped with a platinum thermocouple. The measurement was carried out at $5^{\circ} \mathrm{C}$ intervals from room temperature until decomposition temperature after the sample was heated to a setting temperature and kept to that temperature for about $30 \mathrm{~min}$. IR spectra were measured with a JASCO IR-A3 spectrophotometer in Nujol ${ }^{\circledR}$ mulls.

\section{Results}

Structure of [Ni(diamine) $\left.{ }_{2}\left(\mathrm{H}_{2} \mathrm{O}\right)_{2}\right] \mathrm{X}_{2}$. Electronic spectrometry is quick and effective for a diagnosis of cis or trans isomers of $\left[\mathrm{NiA}_{4} \mathrm{~B}_{2}\right]^{n+}$ type complexes. ${ }^{9-11)}$ In a tetragonal system $\left(D_{4 h}\right)$, six spin-allowed transitions are anticipated, of which four or sometimes five bands are observed in practice. In a $C_{2 v}$ system, more transitions than for a $D_{4 h}$ system are possible, owing to a decrease in symmetry. However, the splittings of the respective terms are small; hence for the cis complex, three rather broad bands are observed, as in the case of the regular $O_{h}$ system.

The electronic spectral data and the configurational assignments of the diaqua complexes are summarized in Table 1, which also includes the data for the anhydrous complexes formed at the elevated temperatures (see later). According to the above diagnosis, all the complexes at room temperature are found to have trans configurations (cf. Fig. 1). In addition, the fact that the peak maxima of the complexes with the same diamine are almost unchanged irrespective of $\mathrm{X}^{-}$ ion yields the formula trans-[Ni(diamine $\left.)_{2}\left(\mathrm{H}_{2} \mathrm{O}\right)_{2}\right] \mathrm{X}_{2}$, where the diamine is $(1 S, 2 S)$-1,2-diphenyl-1,2-ethanediamine $(S$. stien) or (S)-4-methyl-1,2-pentanediamine ( $S$-mpen), and X is $\mathrm{Cl}^{-}, \mathrm{Br}^{-}$, or $\mathrm{NO}_{3}^{-}$.

Thermal Analyses of the Diaqua Complexes. The results of TG-DTA for the diaqua complexes are summarized in Table 2. All the complexes liberated their water molecules endothermically below $115^{\circ} \mathrm{C}$, giving the stable anhydrous products. Both the complex halides of $S$-stien underwent an exothermic reaction at $180-200^{\circ} \mathrm{C}$ (chloride) and at 160 $180^{\circ} \mathrm{C}$ (bromide) upon further heating after dehydration

Table 1. Electronic Spectral Data and Configurational Assignments of the Complexes

\begin{tabular}{|c|c|c|c|c|c|c|c|}
\hline \multirow{2}{*}{$\begin{array}{l}\text { Complex }^{2)} \\
{\left[\mathrm{Ni}(\mathrm{S} \text {-stien })_{2}\left(\mathrm{H}_{2} \mathrm{O}\right)_{2}\right] \mathrm{Cl}_{2} \cdot \mathrm{H}_{2} \mathrm{O}}\end{array}$} & \multirow{2}{*}{$\frac{\text { Temp } /{ }^{\circ} \mathrm{C}}{\mathrm{RT}^{\mathrm{b})}}$} & \multirow{2}{*}{$\frac{\text { Color }}{\text { Violet }}$} & \multicolumn{4}{|c|}{ Band maxima, $\tilde{v} / 10^{3} \mathrm{~cm}^{-1}$} & Configuration \\
\hline & & & 9.4 & 13.4 & 18.3 & $27<$ & trans \\
\hline & 125 & Violet-blue & 9.4 & \multicolumn{2}{|c|}{16.7} & 27.2 & cis \\
\hline & $160^{b)}$ & Blue-violet & 8.1 & $12.7 \mathrm{sh}$ & 17.2 & $27<$ & trans \\
\hline \multirow[t]{2}{*}{$\mathrm{Ni}(\mathrm{S} \text {-stien })_{2}\left(\mathrm{H}_{2} \mathrm{O}_{2}\right] \mathrm{Br}_{2}$} & $\mathrm{RT}^{\mathrm{b})}$ & Violet & 9.4 & 13.4 & 18.3 & $27<$ & trans \\
\hline & $150^{b)}$ & Blue-violet & 7.6 & 14.3 & 17.3 & $27<$ & trans \\
\hline \multirow{2}{*}[\mathrm{Ni}(S\text{-stien})_{2}(\mathrm{H}_{2}\mathrm{O})_{2}]{$\left(\mathrm{NO}_{3}\right)_{2} \cdot 2 \mathrm{H}_{2} \mathrm{O}$} & $\mathbf{R T}^{\mathrm{b})}$ & Violet & 9.2 & 13.4 & 18.0 & $27<$ & trans \\
\hline & $130^{b)}$ & Violet & 8.7 & 13.6 & 18.1 & $27<$ & trans \\
\hline \multirow[t]{2}{*}[\mathrm{Ni}(\mathrm{S}\text{-mpen})_{2}(\mathrm{H}_{2}\mathrm{O})_{2}]{$\mathrm{Cl}_{2} \cdot 1.5 \mathrm{H}_{2} \mathrm{O}$} & RT & Violet & 9.7 & 13.5 & 18.2 & 28.7 & trans \\
\hline & 90 & Violet-blue & 10.1 & \multicolumn{2}{|c|}{17.1} & 27.6 & cis \\
\hline \multirow[t]{2}{*}[\mathrm{Ni}(S\text{-mpen})_{2}(\mathrm{H}_{2}\mathrm{O})_{2}]{$\mathrm{Br}_{2}$} & RT & Violet & 9.4 & 13.4 & 18.4 & 28.6 & trans \\
\hline & $90^{\mathrm{b})}$ & Blue-violet & 7.3 & 13.8 & 17.6 & $27<$ & trans \\
\hline \multirow[t]{2}{*}[\mathrm{Ni}(\mathrm{S}\text{-mpen})_{2}(\mathrm{H}_{2}\mathrm{O})_{2}]{$\left(\mathrm{NO}_{3}\right)_{2} \cdot 0.5 \mathrm{H}_{2} \mathrm{O}$} & RT & Violet & 9.1 & 13.4 & 18.2 & 28.6 & trans \\
\hline & $110^{b)}$ & Violet & 8.3 & .13 .5 & 18.2 & $27<$ & trans \\
\hline \multirow[t]{3}{*}[\mathrm{Ni}(R-\operatorname{chxn})_{2}(\mathrm{H}_{2}\mathrm{O})_{2}]{$\mathrm{Cl}_{2}{ }^{\mathrm{c})}$} & RT & Violet & 9.4 & 13.5 & 18.2 & 28.7 & trans \\
\hline & 90 & Violet-blue & 10.0 & \multicolumn{2}{|c|}{16.8} & 26.9 & cis \\
\hline & 140 & Blue-violet & 8.8 & $-13.3 \mathrm{sh}$ & 17.1 & 28.1 & trans \\
\hline \multirow[t]{2}{*}[\mathrm{Ni}(R-\operatorname{chxn})_{2}(\mathrm{H}_{2}\mathrm{O})_{2}]{$\left.\mathrm{Br}_{2}{ }^{c}\right)$} & RT & Violet & 9.2 & 13.4 & 18.2 & 28.7 & trans \\
\hline & 140 & Violet-blue & 10.0 & \multicolumn{2}{|c|}{16.8} & 26.6 & cis \\
\hline \multirow[t]{2}{*}[\mathrm{Ni}(R-\mathrm{chxn})_{2}(\mathrm{H}_{2}\mathrm{O})_{2}]{$\left(\mathrm{NO}_{3}\right)_{2}{ }^{\mathrm{c})}$} & RT & Violet & 9.2 & 13.6 & 18.1 & 28.6 & trans \\
\hline & 100 & Violet & 10.8 & \multicolumn{2}{|c|}{17.8} & 28.6 & cis \\
\hline
\end{tabular}

a) The formula of the complexes at the elevated temperatures is $\mathrm{NiX}_{2}(\text { diamine })_{2}\left(\mathrm{X}=\mathrm{Cl}^{-}, \mathrm{Br}^{-}\right.$, or $\mathrm{NO}_{3}^{-}$). b) The highest energy band is obscured by a charge transfer band. c) $R$-Chxn is $(1 R, 2 R)-1,2$-cyclohexanediamine and the complexes were reinvestigated in this study. 


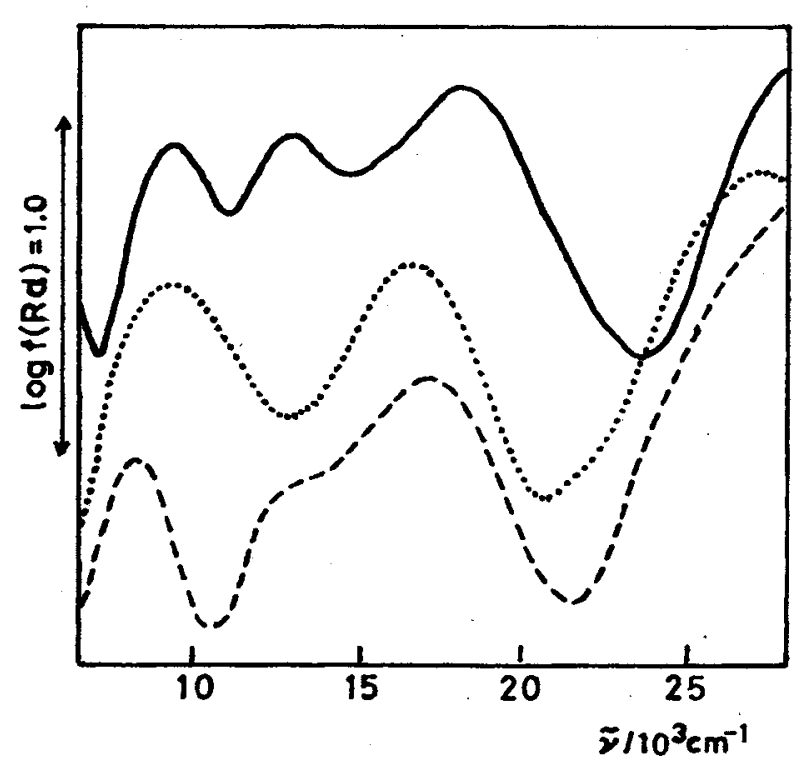

Fig. 1. Solid-phase electronic spectrum of trans-[Ni(Sstien $\left.)_{2}\left(\mathrm{H}_{2} \mathrm{O}\right)_{2}\right] \mathrm{Cl}_{2} \cdot \mathrm{H}_{2} \mathrm{O}$ at room temperature (-) and those of the products at $125^{\circ} \mathrm{C}(\cdots)$ and at $160^{\circ} \mathrm{C}(-\ldots)$.

without any weight losses. The nitrate with $S$-mpen showed a sharp endothermic peak at $185-195^{\circ} \mathrm{C}$, where the anhydrous product melted. Other complexes shoived only slight changes on their DTA curves, except for a large endothermic peak due to the respective dehydration steps.

Electronic Spectral Changes of the Complexes upon Heating. Figure 1 shows the solid-phase electronic spectra of the chloride with $S$-stien at room temperature, at 125 and at $160^{\circ} \mathrm{C}$. The blue-violet species at $160^{\circ} \mathrm{C}$ has a spectral pattern identical with that of the original trans-octahedral species (at room temperature) except for a slight shift of the bands, which indicates a partial exchange of the ligands $\left(\mathrm{H}_{2} \mathrm{O} \rightarrow \mathrm{Cl}^{-}\right)$. On the other hand, the spectrum of the violetblue species at $125^{\circ} \mathrm{C}$ is characteristic of a cis-octahedral structure because the $\mathrm{d}-\mathrm{d}$ bands in the near IR region scarcely show any splittings, to give apparently one peak. Thus, the chloride undergoes thermal deaquation-anation to generate cis-[ $\left[\mathrm{NiCl}_{2}(S \text {-stien })_{2}\right]$, and then the cis complex isomerizes to the trans form upon further heating. The electronic spectral pattern observed at $160^{\circ} \mathrm{C}$ was nearly unchanged after the exothermic reaction occurred at $180-200^{\circ} \mathrm{C}$ on the DTA curve. It seems that the exothermic peak is not associated with drastic changes in structure, while no DTA peaks due to the cis-to-trans isomerization occurring at about $160^{\circ} \mathrm{C}$ could be detected by our experimental conditions.

Table 1 collects the electronic spectral data of all the anhydrous products. It is found that the bromide and nitrate with $S$-stien lose their water molecules to form trans-dianiono species at 150 and $130^{\circ} \mathrm{C}$, respectively. The spectral patterns characteristic of trans- $\left[\mathrm{NiX}_{2}(S \text {-stien })_{2}\right]\left(\mathrm{X}=\mathrm{Br}^{-}\right.$or $\left.\mathrm{NO}_{3}{ }^{-}\right)$ were retained until their decomposition points; the origin of the exothermic peak appearing at $160-180^{\circ} \mathrm{C}$ in the bromide is unknown at present. The overall thermal reactions of the $S$-stien complexes can thus be represented by the following equations:

$$
\begin{aligned}
& \text { trans-[Ni(S-stien } \left.)_{2}\left(\mathrm{H}_{2} \mathrm{O}\right)_{2}\right] \mathrm{Cl}_{2} \\
& \rightarrow \text { cis- }\left[\mathrm{NiCl}_{2}(S \text {-stien })_{2}\right] \rightarrow \text { trans- }\left[\mathrm{NiCl}_{2}(S \text {-stien })_{2}\right] \\
& \text { trans- }\left[\mathrm{Ni}(S \text {-stien })_{2}\left(\mathrm{H}_{2} \mathrm{O}\right)_{2}\right] \mathrm{X}_{2} \\
& \rightarrow \text { trans- }\left[\mathrm{NiX}_{2}(\mathrm{~S} \text {-stien })_{2}\right]\left(\mathrm{X}=\mathrm{Br}^{-} \text {or } \mathrm{NO}_{3}{ }^{-}\right)
\end{aligned}
$$

In the case of the $S$-mpen complexes, the mode of the spectral changes observed in the chloride upon dehydration is very similar to that of the chloride with $S$-stien (Table 1). Thus, the thermal reaction must proceed with a trans-to-cis configurational change during deaquation-anation. On the other hand, the spectral patterns of the bromide and nitrate remain nearly unchanged after dehydration (at 90 and $110^{\circ} \mathrm{C}$, respectively, Table 1), suggesting that a simple deaquationanation takes place and a trans configuration is retained in both cases. The thermal reactions of the $S$-mpen complexes can thus be formulated as follows:

$$
\begin{aligned}
& \text { trans- }\left[\mathrm{Ni}(S \text {-mpen })_{2}\left(\mathrm{H}_{2} \mathrm{O}\right)_{2}\right] \mathrm{Cl}_{2} \rightarrow \text { cis- }\left[\mathrm{NiCl}_{2}(S \text {-mpen })_{2}\right] \\
& \text { trans- }-\left[\mathrm{Ni}(S \text {-mpen })_{2}\left(\mathrm{H}_{2} \mathrm{O}\right)_{2}\right] \mathrm{X}_{2} \\
& \quad \rightarrow \text { trans- }\left[\mathrm{NiX}_{2}(S \text {-mpen })_{2}\right]\left(\mathrm{X}=\mathrm{Br}^{-} \text {or } \mathrm{NO}_{3}{ }^{-}\right)
\end{aligned}
$$

The structures of the dianiono complexes formed just after dehydration were retained until their decomposition temperatures.

All the anhydrous products gradually absorb water molecules to return to the original trans-diaqua complexes on cooling in open air. They repeat the same stereochemical changes upon heating. Accordingly, it is expected that racemization of the diamine ligands does not occur in the course of the thermal treatments.

Table 2. Results of Thermal Analyses

\begin{tabular}{lllll}
\hline \multirow{3}{*}{ Complex } & \multicolumn{2}{c}{ Dehydration } & \multicolumn{2}{c}{$\begin{array}{l}\text { DTA peak temperature } \\
\text { in) }\end{array}$} \\
\cline { 2 - 4 } & $\begin{array}{l}\text { Temperature } \\
\text { in }{ }^{\circ} \mathrm{C}\end{array}$ & $\begin{array}{l}\text { Mass loss } \\
\text { in \% (calcd) }\end{array}$ & $\begin{array}{l}\text { Endo } \\
\text { Endo }\end{array}$ & Exo \\
\hline trans- $\left[\mathrm{Ni}(S \text {-stien })_{2}\left(\mathrm{H}_{2} \mathrm{O}\right)_{2}\right] \mathrm{Cl}_{2} \cdot \mathrm{H}_{2} \mathrm{O}$ & $50-110$ & $8.0(8.9)$ & - & $180-200$ \\
trans- $\left[\mathrm{Ni}(S \text {-stien })_{2}\left(\mathrm{H}_{2} \mathrm{O}\right)_{2}\right] \mathrm{Br}_{2}$ & $75-115$ & $4.9(5.3)$ & - & $160-180$ \\
trans- $\left.\left[\mathrm{Ni}(S \text {-stien })_{2}\left(\mathrm{H}_{2} \mathrm{O}\right)_{2}\right] \mathrm{NO}_{3}\right)_{2} \cdot 2 \mathrm{H}_{2} \mathrm{O}$ & $60-85$ & $8.7(10.6)$ & - & - \\
trans- $\left[\mathrm{Ni}(S \text {-mpen })_{2}\left(\mathrm{H}_{2} \mathrm{O}\right)_{2}\right] \mathrm{Cl}_{2} \cdot 1.5 \mathrm{H}_{2} \mathrm{O}$ & $\mathrm{RT}-60$ & $13.5(14.8)$ & - & - \\
trans- $\left[\mathrm{Ni}(S \text {-mpen })_{2}\left(\mathrm{H}_{2} \mathrm{O}\right)_{2}\right] \mathrm{Br}_{2}$ & $45-65$ & $7.5(7.4)$ & - & - \\
trans- $\left[\mathrm{Ni}(S \text {-mpen })_{2}\left(\mathrm{H}_{2} \mathrm{O}\right)_{2}\right]\left(\mathrm{NO}_{3}\right)_{2} \cdot 0.5 \mathrm{H}_{2} \mathrm{O}$ & $40-60$ & $9.9(9.8)$ & $185-195$ & - \\
\hline
\end{tabular}

a) This was estimated from the TG data. - b) Endothermic reaction due to dehydration is excluded. 


\section{Discussion}

The structures of the anhydrous products obtained by thermal deaquation-anation are compared with those ${ }^{3,6)}$ of the complexes containing the corresponding racemic diamines in Table 3. The table also contains the data of $(1 R, 2 R)-1$, 2-cyclohexanediamine $\left(R\right.$-chxn) complexes ${ }^{2.5)}$ which were reinvestigated in this study by a method of high-temperature electronic spectrometry (cf. Table 1). The structure of the anhydrous nitrate with $R$-chxn was determined to be $c i s-$ $\left[\mathrm{Ni}\left(\mathrm{NO}_{3}\right)(R \text {-chxn })_{2}\right] \mathrm{NO}_{3}$, in which free and bidentate $\mathrm{NO}_{3}{ }^{-}$ ions coexist, from the pattern ${ }^{12,13)}$ of weak combination bands due to $\mathrm{NO}_{3}{ }^{-}$ions appearing at $1700-1800 \mathrm{~cm}^{-1}$ in the $\mathrm{IR}$ spectrum.

All the diamines produce complexes with the same composition and structure, ${ }^{14)}$ trans-[Ni(diamine $\left.)_{2}\left(\mathrm{H}_{2} \mathrm{O}\right)_{2}\right] \mathrm{X}_{2}$, as the starting materials of thermal reaction. However, there are notable differences between the structures of the anhydrous complexes with the racemic diamines and those with the corresponding optically active diamines, as shown in Table 3; a cis configuration is rather favored in the optically active diamine complexes. In addition, two complex chlorides with $S$-stien and $R$-chxn display thermally induced $c i s-$ to-trans isomerization after dehydration. This isomerization could not be detected even by a highly sensitive DSC measurement (sensitivity, $10 \mathrm{~mJ} / \mathrm{sec} /$ full scale; heating rate, $5^{\circ} \mathrm{C} \mathrm{min}^{-1}$; gas flow, $\mathrm{N}_{2}$ at $100 \mathrm{ml} \mathrm{min}^{-1}$; sampling weight, ca. $10 \mathrm{mg}$ ), so that the enthalpy changes are expected to be less than a few $\mathrm{kJ} \mathrm{mol}^{-1}$ and remarkably lower than those $\left(-20--60 \mathrm{~kJ} \mathrm{~mol}^{-1}\right)$ of the irreversible exothermic cis-totrans or trans-to-cis isomerization observed in the same type of chromium(III) complexes, $\left[\mathrm{CrX}_{2}\right.$ (diamine) $\left.{ }_{2}\right] \mathrm{X}^{15)}$ (where diamine is rac-2,3-butanediamine, rac-chxn or rac-2,4-pentanediamine, and $\mathrm{X}_{\text {is }} \mathrm{Cl}^{-}$or $\mathrm{Br}^{-}$). This indicates that the energy differences between the cis and trans configurations for both the dichloro complexes are very small. This isomerization is irreversible and the trans-dichloro complexes (the final products) directly revert to the original trans-diaqua complexes on cooling in open air.

The fact that the structures of the anhydrous complexes with the optically active diamines differ from those of the corresponding racemic diamines must be ascribed to a slight difference in the conformation of diamine ligands between,

Table 3. Structures of the Anhydrous Complexes $\left.\left(\left[\mathrm{NiX}_{2} \text { (diamine) }\right)_{2}\right]\right)$

\begin{tabular}{llll}
\hline Diamine & $\mathrm{X}$ is $\mathrm{Cl}^{-}$ & $\mathrm{X}$ is $\mathrm{Br}^{-}$ & $\mathrm{X}$ is $\mathrm{NO}_{3}^{-}$ \\
\hline$S$-stien & cis $\rightarrow$ trans) & trans & trans \\
$S$-mapen & cis & trans & trans \\
$R$-chxn & cis $\rightarrow$ trans) & cis & cis ${ }^{\mathrm{b})}$ \\
rac-stien & trans & trans & trans \\
rac-mpen & trans & trans & trans \\
rac-chxn & trans & trans & trans \\
\hline
\end{tabular}

a) This implies that cis complex formed just after dehydration isomerizes to the trans complex upon further heating. b) cis$\left[\mathrm{Ni}\left(\mathrm{NO}_{3}\right)(R-\text { chxn })_{2}\right]_{\mathrm{NO}_{3}}$ (see text). for example, trans- $\left[\mathrm{Ni}(S\right.$-stien $)(S$-stien $\left.)\left(\mathrm{H}_{2} \mathrm{O}\right)_{2}\right] \mathrm{X}_{2}$ and trans$\left[\mathrm{Ni}(R\right.$-stien $)(S$-stien $\left.)\left(\mathrm{H}_{2} \mathrm{O}\right)_{2}\right] \mathrm{X}_{2}$; in both complexes all the phenyl groups are expected to protrude towards an equatorial direction on the chelate plane, with the result that trans$\left[\mathrm{Ni}(S \text {-stien })_{2}\left(\mathrm{H}_{2} \mathrm{O}\right)_{2}\right] \mathrm{X}_{2}$ obtained for $S$-stien belongs to $D_{2}$ point group symmetrically, while trans-[Ni(R-stien)( $S$-stien)$\left.\left(\mathrm{H}_{2} \mathrm{O}\right)_{2}\right] \mathrm{X}_{2}$ obtained for rac-stien is $C_{2 h}$. It is interesting that nickel(II) ions accept a pair of $d$ - and $l$-form diamines on complexation with the racemic diamines, forming trans-[Ni( $R$-diamine)( $S$-diamine) $\left.\left(\mathrm{H}_{2} \mathrm{O}\right)_{2}\right] \mathrm{X}_{2}$; it has been confirmed by $\mathrm{X}$-ray analysis that rac-chxn complexes crystallize as trans$\left.\left[\mathrm{Ni}(R-\operatorname{chxn})(\mathrm{S}-\mathrm{chxn})\left(\mathrm{H}_{2} \mathrm{O}\right)_{2}\right] \mathrm{X}_{2} \cdot{ }^{16}\right)$

However, the stability constants of nickel(II) complexes with racemic and the optically active ethylenediamines are almost the same. ${ }^{17)}$ Thus, this discrimination may not be due to a stereoselectivity of nickel(II) ions for the racemic diamines, but rather would result from a difference in the solubilities of trans- $\left[\mathrm{Ni}(R\right.$-diamine $)(S$-diamine $\left.)\left(\mathrm{H}_{2} \mathrm{O}\right)_{2}\right] \mathrm{X}_{2}$ and trans- $[\mathrm{Ni}$ (R-diamine $\left.)_{2}\left(\mathrm{H}_{2} \mathrm{O}\right)_{2}\right] \mathrm{X}_{2}$ (or trans- $\left[\mathrm{Ni}(\mathrm{S} \text {-diamine })_{2}\left(\mathrm{H}_{2} \mathrm{O}\right)_{2}\right]-$ $\mathrm{X}_{2}$ ) for the solvents used in the preparations of the complexes; it seems reasonable to assume that trans-[Ni( $R$ diamine)( $(S$-diamine $\left.)\left(\mathrm{H}_{2} \mathrm{O}\right)_{2}\right]_{\mathrm{X}_{2}}$ preferentially separated out under our experimental conditions.

What are the reasons for the differences in the thermal reactions of the optically active and racemic diamine complexes? For example, the structural change from trans-[Ni(Sstien $\left.)_{2}\left(\mathrm{H}_{2} \mathrm{O}\right)_{2}\right] \mathrm{X}_{2}$ to cis- $\left[\mathrm{NiX}_{2}(S \text {-stien })_{2}\right]$ results in the decrease in symmetry $\left(D_{2} \rightarrow C_{2}\right)$, while if trans- $[\mathrm{Ni}(R$-stien $)(S-$ stien $\left.)\left(\mathrm{H}_{2} \mathrm{O}\right)_{2}\right] \mathrm{X}_{2}$ changes to cis- $\left[\mathrm{NiX}_{2}(R\right.$-stien $)(S$-stien) $]$, the decrease is from $C_{2 h}$ to $C_{1}$. The same situation can be applied to the case of the chxn complexes. There were no examples of $C_{2 h} \rightarrow C_{1}$ change as shown in Table 3 ; all the diaqua complexes with the rac-diamines maintained their symmetry in the anhydrous complexes. It is understandable that, only from the discussion on symmetry, the $(R)(R)$ - or $(S)(S)$-conformation is more advantageous for the formation of a cis complex than the $(R)(S)$-conformation. Although the experimental results support this reasoning, it is not clear at present how such conformational differences in diamine ligands and the properties of counter anions affect the thermal reactions. However, the results of this study give an explanation for a variety observed in colors and stereochemistry of Lifschitz complexes.

This work was partially supported by Grants-in-Aid for Scientific Research (C) (No. 07640741) from the Ministry of Education, Science, Sports and Culture.

\section{References}

1) I. Lifschitz, J. G. Bos, and K. M. Dijkema, Z Anorg. Allg. Chem. 242, 97 (1939).

2) Y. Thara, Netsu Sokutei, 17, 16 (1990).

3) Y. Thara and R. Tsuchiya, Bull. Chem. Soc. Jpm, 57, 2829 (1984).

4) Y. Thara and R. Nakamura, Thermochim. Acta, in press.

5) Y. Ihara, S. Naride, and A. Uehara, Thermochim. Acta, 200, 327 (1992). 
6) Y. Thara and T. Fukui, Thermochim. Acta, 236, 199 (1994).

7) L. Arpesella, A. La Manna, and M. Grassi, Gazz. Chim. Ital, 85, 1354 (1955).

8) Y. Yano, M. Saburi, S. Yoshikawa, and J. Fujita, Bull. Chem. Soc. Jpn, 49, 101 (1976).

9) A. B. P. Lever, Coord. Chem. Rev., 43, 63 (1982).

10) S. Koner, A. Ghosh, and N. Ray Chaudhuri, J. Chem. Soc., Dalton Trans., 1990, 1563.

11) D. Das, A. Ghosh, and N. Ray Chaudhuri, Bull. Chem. Soc. Jpn., 67, 3254 (1994).

12) A. B. P. Lever, E. Mantovani, and B. S. Ramaswamy, Can. J. Chem., 49, 1957 (1971).
13) Y. Fukuda, R. Morishita, and K. Sone, Bull. Chem. Soc. Jpn., 49, 1017 (1976).

14) It can be anticipated that, in the case of $S$-mpen complexes, the two isopropylated carbon atoms occupy axial sites distant from each other to minimize their steric hindrance. C. J. Hawkins and M. L. McEniery, Aust. J. Chem., 31, 1699 (1978).

15) R. Tsuchiya, A. Uehara, and T. Yoshikuni, Inorg. Chem., 21, 590 (1982).

16) A. V. Capilla, R. A. Aranda, and F. G. Bertran, Cryst. Struct. Chem., 9, 147 (1980).

17) A. E. Martell and R. M. Smith, in "Critical Stability Constants," Plenum Press, New York (1975), Vol. 2. 